\title{
Accessibility and Consumption of Alcoholic Drinks in Metro Manila Colleges and Universities
}

\author{
Paulo Ma. N. Pagkatipunan \\ Department of Ophthalmology and Visual Sciences, College of Medicine and Philippine General Hospital, University of the Philippines Manila
}

\begin{abstract}
Objective. Alcohol consumption of university students in Metro Manila was determined and compared to other countries in the region and in the West.

Methods. A survey of students from ten randomly selected public and private universities in Metro Manila was done.

Results. A total of 2,930 students participated, $46.1 \%$ from public schools and $58.9 \%$ were female. Of the total students, $81.6 \%$ had drank an alcoholic drink in their lifetime; and 15.6\% drank beer, $22.5 \%$ drank wine and $11.4 \%$ drank distilled spirits before they were 13 years old. For the past 30 days, 30.2\% drank beer, 30.8\% distilled spirit and $18.7 \%$ wine; $16.9 \%, 7.4 \%$ and $19.7 \%$ binged on beer, wine and distilled spirits, respectively; and $29.1 \%$ got drunk. Five percent of the students had drank inside their school. Of those who drove any motorized vehicle, $28.9 \%$ drove when they had drank and of those who use prohibited drugs, $66.7 \%$ mixed the two. Thirty one percent said they tried to quit drinking in the past 12 months and $7.5 \%$ admitted they have a drinking problem.
\end{abstract}

Conclusion. Alcohol consumption of Metro Manila students approximates those of other countries. For policy and monitoring purposes, it is recommended that this survey be done regularly with a nationwide scope and compare this with other countries for best practices.

Key Words: college drinking, underage drinking, binge drinking

\section{Introduction}

Schools are institutions where most people spend their early years and where most adult behaviors are formed. Therefore, any behavior developed at this stage, like alcohol consumption, may be carried on to adulthood.

Presented as a poster entitled "Alcohol Accessibility and Consumption in Metro Manila Colleges and Universities" at the 15th National Health Research Forum for Action: Bridging Theory and Practice to achieve Kalusugan Pangkalahatan, October 21-22, 2014, Mariott Hotel, Pasay City, Philippines.

Corresponding author: Paulo Ma. N. Pagkatipunan, MD, MHA, DPA, DrPH Department of Ophthalmology and Visual Sciences

Philippine General Hospital

University of the Philippines Manila

Taft Avenue, Ermita, Manila 1000 Philippines

Telephone: +6325548394

Email: paulomnp@yahoo.com
Consequently, the Department of Health saw it fit to conduct a research on Metro Manila college students as a starting point before doing a countrywide survey. Alcohol consumption data is important, at the very least, for policy and monitoring purposes. Moreover, admittedly, the DOH lacks data on any kind of alcohol consumption in the country.

This study determined the alcohol consumption of university students in the Metro Manila area and compares them with existing data of other countries in the region and the West. Comparisons are made with high school students in other countries because the data from this survey was taken in 2013, before the implementation of K-12 hence agewise, they are comparable. ${ }^{1}$

\section{Methods}

Before the start of the study, the protocol was submitted and was approved for commencement by the Department of Health Research Ethics Review Committee. Incorporated in the approval were the consent forms for the survey participants of legal age and assent forms for those less than 18 years old.

For this cross-sectional study, the sampling design included taking a list of colleges and universities in Metro Manila obtained from the website of the Commission on Higher Education. Schools were categorized into public and private. With a target of four public schools and four private schools (total of 8 schools), six in each category of school were randomly selected from the list for a total of 12 schools (regardless of their enrolment size) in case of school refusals and therefore the next randomly selected school will be part of the study.

One public school refused participation in the study therefore, the next consecutive randomly chosen public school was invited to fill in the required number of public schools. Two private schools had less than the target sample size, therefore, an addition of 2 private schools were invited. A total of 6 private schools and 4 public schools became part of the study. All schools were anonymized.

The sampling design employed for the selection of students included randomly selecting eight programs from each school. Each year level was properly represented by two randomly selected programs accordingly to a set of 75 students for each year level. Classes were the units of sampling and were randomly selected according to 
programs. If the consenters in the study did not reach the proposed number in the class, additional class/es in the same course were randomly selected to fulfill the desired number. Therefore, selected programs may be different per schools.

For the survey, 300 students (Figure 1) in each of the eight schools were targeted. After pre-tests were done by $\mathrm{DOH}$, questionnaires were given to the students after a brief introduction and after informed consent forms were signed.

$$
\mathrm{n}=\frac{\mathrm{Z}^{2} \mathrm{PQ}}{\mathrm{d}^{2}}=\frac{(1.96)^{2}(15)(85)}{1.5^{2}}=2177
$$

where: $Z=1.96$ corresponding to $95 \%$ confidence interval

$\mathrm{P}=$ proportion of subjects with the characteristics ${ }^{6,18}$

$\mathrm{Q}=100-\mathrm{P}$

$\mathrm{d}^{2}=$ error

Figure 1. Sample Size calculation.

\section{Results and Discussions}

A total of 2,930 students from ten colleges and universities in Metro Manila participated with 1,351 (46.1\%) from public schools and 1,579 (53.9\%) from private schools. There was almost equal distribution of students by year level, and $58.9 \%$ were females. About $85.0 \%$ of respondents have an age range of 16-20 years.

\section{Ever Drank Alcohol}

In Metro Manila, $81.6 \%$ of college students were ever drinkers. This is defined as those who had at least one alcoholic drink in their life. ${ }^{2,3}$ The prevalence was higher in males $(83.1 \%)$ than females $(80.6 \%)$ and also higher in private schools $(83.9 \%)$ than in public schools $(78.8 \%)$ which may mean that those in private universities may have more access, financially, to alcoholic drinks. In the United States, $70.0 \%$ to $80.0 \%$ of high school students would have had at least one serving of alcohol by the time they graduate high school which approximates our finding in this study.2,4

\section{Drank Alcohol Before 13 Years}

In Metro Manila, more college students in private schools drank alcoholic drinks before age 13 than those in the public schools, majority of whom are males.

Generally, $15.6 \%$ of college students drank beer, $22.5 \%$ drank wine and $11.4 \%$ drank distilled spirits before they were 13 years old. These results were almost the same as the Global School-based Student Health Survey, a study of high school students done in several countries by the World Health Organization and the United States of America, Centers for Disease Control and Prevention, which showed that in the Philippines in 2003, 18.9\% drank before 13 years old while in 2011 the prevalence was $18.7 \% .5$,6 These figures are relatively low compared to the prevalence in other Asian countries - Thailand 76.5\%, Malaysia 69.6\%, Vietnam $47.2 \%$ and Cambodia $30.3 \% .^{7-10}$
In the United States, $20.5 \%$ of students had drunk alcohol for the first time before age 13 and the average age where young people began drinking was 13 years old while in Europe, it was 11 years old. 4,11,12 This is important because if one started drinking at age 15 years old, they have 4 times more chance to develop alcohol dependence and abuse as against those who started at age 21. ${ }^{3}$ They are also more likely to experience alcohol-related unintentional injuries and be involved in fights. ${ }^{13}$ And young brains are more susceptible to toxic effects of alcohol. ${ }^{14}$

\section{Current Drinkers}

The prevalence of current alcohol use, defined as those who had had at least one drink of alcohol on at least one day during the 30 days before the survey, in Metro Manila college students was $30.2 \%, 18.7 \%$ and $30.8 \%$ for beer, wine and distilled spirits, respectively. ${ }^{2}$ The prevalence was more in private schools than in public schools and current usage is more in males.

The Philippine Global School-based student Health Survey 2003 survey showed that $18.2 \%$ of students drank at least one drink containing alcohol in the last 30 days, while it was $18.7 \%$ in the 2011 Global School-based student Health Survey. ${ }^{5}$ Both surveys showed a predominance of males. There seems to be a status quo for prevalence of current drinkers and for both sexes in the last 10 years at least for high school students. In Metro Manila colleges, 30.2\% are current drinkers with a prevalence of males. This shows that more Metro Manila college students drank in the last 30 days than high school students in the Philippines.

The proportion of current drinkers in the Global Student-based Health Survey of neighboring countries showed the following: Thailand (2008) 14.8\%; Malaysia (2012) 4.7\%; Vietnam (2013) 23.7\%; Cambodia (2013) 7.3\%; China (Beijing) 13.0\%; and Indonesia (2007) 2.6\%. ${ }^{7-10,15,16}$ This showed that more college students in Metro Manila drank in the last 30 days than high school students in some Asian countries. All the surveys above, including this study, showed a predominance of males.

On the other hand, in the United States, several studies showed that approximately $40.0 \%$ to $50.0 \%$ of high school students had had a drink of alcohol in the last 30 days.

\section{Heavy Drinking}

In Metro Manila, $16.9 \%$ of students drank 5 or more glasses of beer in the last 30 days; $7.4 \%$ drank 5 or more glasses of wine and $19.7 \%$ drank 5 or more glasses of distilled spirits. The study showed that the private school students significantly drank more in the last 30 days than the public school students and with more males involved in this heavy drinking.

It has been shown that individuals who increase their heavy drinking from age 18 to 24 and those who consistently had 5 or more servings of alcoholic drink at least once a 
week during this period may have problems attaining the goals typical of the transition from adolescence to young adulthood (e.g., marriage, educational attainment, employment, and financial independence). ${ }^{17}$

\section{Being Drunk}

In Metro Manila, 29.1\% of college students got drunk in the past 30 days (Table 1) which is significantly more prevalent in the private schools. Also, considerably more in males got drunk.

Table 1. Distribution of respondents by school and sex and whether they got drunk at least once in the last month

\begin{tabular}{|c|c|c|c|c|c|c|c|c|c|c|}
\hline & \multicolumn{4}{|c|}{ School } & \multicolumn{4}{|c|}{ Sex } & \multirow{2}{*}{\multicolumn{2}{|c|}{ Total }} \\
\hline & \multicolumn{2}{|c|}{ Private } & \multicolumn{2}{|c|}{ Public } & \multicolumn{2}{|c|}{ Female } & \multicolumn{2}{|c|}{ Male } & & \\
\hline & No. & $\%$ & No. & $\%$ & No. & $\%$ & No. & $\%$ & No. & $\%$ \\
\hline Yes & 549 & 34.8 & 303 & 22.4 & 436 & 25.3 & 416 & 34.6 & 852 & 29.1 \\
\hline No & 1,029 & 65.2 & 1,048 & 77.6 & 1,289 & 74.7 & 788 & 65.4 & 2,077 & 70.9 \\
\hline Total & 1,578 & 100 & 1,351 & 100 & 1,725 & 100 & 1,204 & 100 & 2,929 & 100 \\
\hline $\mathrm{x}^{2}, \mathrm{p}$-value & & 53.93, & $<0.0001$ & & & 29.58, & $<0.0001$ & & & \\
\hline
\end{tabular}

To compare, the following is a survey of drinking among 15- to 16-year-old students in selected Western countries in 2003 where they had been drunk at least once in the last 30 days: $18.0 \%$ (France); $49.0 \%$ (Denmark); $12.0 \%$ (Italy); $17.0 \%$ (Sweden); 33.0\% (United Kingdom); and 18.0\% (USA). ${ }^{18}$

This means that more Metro Manila college students felt that they got drunk in the last month than 15- to 16-yearsolds in France, Italy, Sweden and the United States. It should be considered that being drunk is subjective, and not associated with the amount of alcohol that had been drank. It is when the person feels that he/she may be losing much of his/her mental and physical control. About 30\% of Metro Manila college students are at increased risk of the acute consequences of being drunk and this includes injuries, unprotected sex and automobile crashes.

\section{Drank Alcohol on School Property}

Though there are only eight schools out of the ten in the study which have alcohol related policies, still 5.0\% of Metro Manila students had ever drank inside their school with a predominance again of males (Table 2). When asked if they drank inside the school, $6.2 \%$ from private schools and $3.7 \%$ from public schools said yes. The same prevalence can be seen in the United States where $5.1 \%$ of students had drank at least one drink of alcohol on school property on at least one day in the last 30 days. $^{2}$

Table 2. Distribution of respondents by school and sex and having drank inside their school

\begin{tabular}{ccccccccccc}
\hline & \multicolumn{4}{c}{ School } & \multicolumn{4}{c}{ Sex } & \multicolumn{2}{c}{ Total } \\
& \multicolumn{1}{c}{ Private } & \multicolumn{2}{c}{ Public } & \multicolumn{2}{c}{ Female } & \multicolumn{2}{c}{ Male } & \multicolumn{2}{c}{} \\
& No. & $\%$ & No. & \% & No. & $\%$ & No. & $\%$ & No. & $\%$ \\
\cline { 2 - 11 } $\mathrm{x}^{2}$, p-value & 98 & 6.2 & 49 & 3.7 & 64 & 3.7 & 83 & 7.0 & 147 & 5.0 \\
\hline
\end{tabular}

\section{Parents knowing that they Drink Alcohol}

There were $61.6 \%$ of the private school students and $57.4 \%$ of the public school students who had parents who knew they were drinking alcoholic beverages. Moreover, almost equal proportion of male $(61.2 \%)$ and female $(58.6 \%)$ students said that their parents knew they drink.

Among private school students, $35.5 \%$ had parents knew how much they drank while it was $38.8 \%$ in public schools. Almost equal proportion of male $(36.5 \%)$ and female $(37.4 \%)$ students had parents who knew how much they drink.

This data is important because parent-child relationship has a very significant amount of impact to alcohol-drinking behavior and that $89.0 \%$ of young adults in the United States said that parents are the leading influence to decide not to drink. ${ }^{19-22}$ It seems that Metro Manila parents are permissive in terms of letting their college children drink alcoholic beverages.

\section{Mixed Alcohol with Driving}

Among Metro Manila students, 19.9\% from private and $11.2 \%$ from public schools drove a car, motorcycle or any motorized vehicle. Of those who drove, 33.8\% from private schools and $18.7 \%$ from public schools said they had mixed drinking and driving (Table 3). Moreover, $15.1 \%$ of the females and $38.0 \%$ of the males who drove a motorized vehicle had an instance of drinking and driving.

Table 3. Distribution of respondents by school and sex and whether they had mixed drinking and driving

\begin{tabular}{|c|c|c|c|c|c|c|c|c|c|c|}
\hline & \multicolumn{4}{|c|}{ School } & \multicolumn{4}{|c|}{ Sex } & \multirow{2}{*}{\multicolumn{2}{|c|}{ Total }} \\
\hline & \multicolumn{2}{|c|}{ Private } & \multicolumn{2}{|c|}{ Public } & \multicolumn{2}{|c|}{ Female } & \multicolumn{2}{|c|}{ Male } & & \\
\hline & No. & $\%$ & No. & $\%$ & No. & $\%$ & No. & $\%$ & No. & $\%$ \\
\hline Yes & 106 & 33.8 & 28 & 18.7 & 28 & 15.1 & 106 & 38 & 134 & 28.9 \\
\hline No & 208 & 66.2 & 122 & 81.3 & 157 & 84.9 & 173 & 62.0 & 330 & 71.1 \\
\hline Total & 314 & 100 & 150 & 100 & 185 & 100 & 279 & 100 & 464 & 100 \\
\hline$x^{2}, p$-value & & 11.26, & 0.001 & & & 28.30, & 0.000 & & & \\
\hline
\end{tabular}

According to the Philippine Department of Health Online National Electronic Injury Surveillance System Factsheet, topping the list of the reported risk factors for transport/vehicular crash related injury cases, covering all ages and gender, was alcohol/liquor. ${ }^{23}$ Annual quarterly comparison from 2010 to 2013 showed that, with the exception of the 3rd quarter of 2012, there is a decreasing trend of those having injuries from vehicular accidents due to drinking alcohol.

In the United States, motor vehicle crashes were the leading cause of death among youth ages 15 to 20 years, and the rate of fatal crashes among alcohol-involved drivers between 16 and 20 years old was more than twice the rate for alcohol-involved drivers 21 and older. In the United States, alcohol use was also linked with youthful deaths by drowning, suicide, and homicide and annually, about 5,000 people under age 21 die from alcohol-related injuries 
involving underage drinking. ${ }^{24}$ Approximately 1,900 (38.0\%) of the 5,000 deaths involve motor vehicle crashes. ${ }^{25,26}$

\section{Mixed Alcohol with other Drugs}

Use of any prohibited drugs by students are $3.8 \%$ in private schools and $1.9 \%$ in public schools. Seventy percent $(70.0 \%)$ of those respondents who used prohibited drugs in private schools and $58.3 \%$ of those in public schools had tried mixing drugs with alcohol (Table 4). Of those who tried drugs, $71.4 \%$ of the females and $64.3 \%$ of the males mixed it with alcohol.

Table 4. Distribution of respondents by school and sex and whether they had mixed alcohol and prohibited drugs

\begin{tabular}{|c|c|c|c|c|c|c|c|c|c|c|}
\hline & \multicolumn{4}{|c|}{ School } & \multicolumn{4}{|c|}{ Sex } & \multirow{2}{*}{\multicolumn{2}{|c|}{ Total }} \\
\hline & \multicolumn{2}{|c|}{ Private } & \multicolumn{2}{|c|}{ Public } & \multicolumn{2}{|c|}{ Female } & \multicolumn{2}{|c|}{ Male } & & \\
\hline & No. & $\%$ & No. & $\%$ & No. & $\%$ & No. & $\%$ & No. & $\%$ \\
\hline Yes & 42 & 70 & 14 & 58.3 & 20 & 71.4 & 36 & 64.3 & 56 & 66.7 \\
\hline No & 18 & 30.0 & 10 & 41.7 & 8 & 28.6 & 20 & 35.7 & 28 & 33.3 \\
\hline Total & 60 & 100 & 24 & 100 & 28 & 100 & 56 & 100 & 84 & 100 \\
\hline $\mathrm{x}^{2}, \mathrm{p}$-value & & 1.05, & 0.306 & & & 0.43 , & .513 & & & \\
\hline
\end{tabular}

Alcohol use was associated with many adolescent risk behaviors, including other drug use and delinquency, weapon carrying and fighting, and perpetrating or being the victim of date rape. ${ }^{23}$ This may lead credence to several studies that alcohol is sometimes referred to as a "gateway drug". 27,28

\section{Felt having a Drinking Problem}

Almost ten percent $(9.6 \%)$ respondents from private schools and $5.0 \%$ from public schools felt they had a drinking problem of which $6.3 \%$ were females and $9.2 \%$ were males. In the last 12 months, $29.5 \%$ of private school students and $32.8 \%$ of public school students tried to quit drinking. By sex, $32.3 \%$ of them were females and $29.3 \%$ were males.

\section{Conclusion}

In conclusion, alcohol consumption of Metro Manila students have been documented and compared to high school surveys in other countries in the region and other western countries, and it was found that their values approximate each other. Even though the comparison was between college students in Metro Manila and high school students from other countries, the comparison is valid in terms of age of both respondents. The consumption of alcohol was also statistically more prevalent in private colleges and the male gender.

As in other countries, regulations should be put in place to reduce college drinking. One of these is the restriction of density of outlets/stores and regulation of alcohol promotion and advertisements outside schools.

It is further recommended that surveys be done every 3 to 5 years with a nationwide scope to show the country prevalence results and to show trends which may dictate on national policies regarding alcohol consumption. Such surveys should be compared with other countries, especially in the Southeast Asian region to emulate best practices to curb underage drinking and excessive drinking in the youth.

\section{Statement of Authorship}

The author of this study has approved the final version submitted

\section{Author Disclosure}

The author declared no conflicts of interest. The original research of the study on which this journal article was based, was commissioned by the Department of Health for its 2012 Health Systems Research Management, in support of Universal Health Care in the Philippines. The views and opinions contained in this article were those of the author and do not necessarily represent those of the Philippine Department of Health.

\section{Funding Source}

This paper was funded by the Department of Health (DOH) through the Department of Science and Technology (DOST).

\section{References}

1. Index mundi. Philippines Demographics Profile [Online]. 2013 [cited 2016 April 19]. Available from http://www.indexmundi.com/ philippines/demographics_profile.html.

2. Eaton DK, Kann L, Kinchen S, et al. Youth Risk Behavior SurveillanceUnited States, 2011. Center for Disease Control. MMWR Surveill Summ. 2012; 61(4):1-162.

3. National Institute on Alcohol Abuse and Alcoholism. NIAAA Factsheet [Online]. 2011 [cited 2016 May 2]. Available from http://pubs.niaaa. nih.gov/publications/Newsletter/Spring2011/newpub.htm.

4. U.S. Department of Health and Human Services. The Surgeon General's Call to Action To Prevent and Reduce Underage Drinking. U.S Department of Health and Human Services, Office of the Surgeon General [Online]. 2007 [cited 2016 April 12]. Available from http://www.ncbi.nlm.nih.gov/books/NBK44360/.

5. World Health Organization. Geneva: Global School-Based Student Health Survey [Online]. 2004 [cited 2016 April 19]. Available from http://www. wpro.who.int/topics/adolescent_health/philippines_fs.pdf.

6. World Health Organization. Global School-Based Student Health Survey [Online]. 2011 [cited 2016 April 19]. Available from http://www.who.int/ chp/gshs/2011_GSHS_FS_Philippines.pdf.

7. World Health Organization. Global School-Based Student Health Survey [Online]. 2008 [cited 2016 April 19]. Available from http://www.who.int/ chp/gshs/GSHS_FINAL_Report_Thailand_2008.pdf.

8. World Health Organization. Global School-Based Student Health Survey [Online]. 2012 [cited 2014 April 19]. Available from http://www.cdc.gov/ gshs/countries/seasian/pdf/2012ysbh_factsheet.pdf.

9. World Health Organization. Global School-Based Student Health Survey [Online]. 2013 [cited 2016 April 19]. Available from http://www.who.int/ chp/gshs/2013_Viet_Nam_Fact_Sheet.pdf.

10. World Health Organization. Global School-Based Student Health Survey [Online]. 2013 [cited 2014 April 19]. Available from http://www.who.int/ chp/gshs/2013_Cambodia_GSHS_Fact_Sheet.pdf.

11. Ahlstrom SK, Osterberg EL. International perspectives on adolescent and young adults drinking. Alcohol Res Health. 2004; 28(4):258-68.

12. Jernigan DH. Global status report: Alcohol and young people. Geneva. World Health Organization [Online]. 2001 [cited 2016 May 2]. Available from http://apps.who.int/iris/handle/10665/66795. 
13. Hingson RW, Heeren T, Jamanka A, Howland J. Age of drinking onset and unintentional injury involvement after drinking. JAMA. 2000; 284(12):1527-33.

14. White AM, Swartzwelder HS. Age-related effects of alcohol on memory and memory-related brain function in adolescents and adults. Recent Dev Alcohol. 2005; 17:161-76.

15. Center for Disease Control and Prevention. Global School-Based Student Health Survey [Online]. 2003 [cited 2016 April 19]. Available from http://www.who.int/chp/gshs/2003_China_Beijing_fact_sheet.pdf.

16. Center for Disease Control and Prevention. Global School-Based Student Health.

17. Survey (GSHS) [Online]. c2007 [cited 2016 April 19]. Available from http://www.who.int/chp/gshs/2007_Indonesia_fact_sheet.pdf.

18. Schulenberg J, O'Malley PM, Backman JG, Wadsworth KN, Johnston LD. Getting drunk and growing up: trajectories of frequent binge drinking during the transition to young adulthood. J Stud Alcohol. 1996; 57(3):289-304

19. Hibell B, Guttormsson U, Ahlstrom S, et. al. (The Swedish Council for Information on Alcohol and other Drugs, Stockholm, Sweden). The 2007 European School Survey Project on Alcohol and other Drugs Report: Substance Use Among European Countries. Report. Stockholm. The Swedish National Institute of Public Health 2009.

20. Wood MD, Read JP, Mitchell RE, Brand NH. Do parents still matter? Parents and peer influence on alcohol involvement among recent high school graduates. Psychol Addict Behav. 2004; 18(1):19-30.

21. Ryan SM, Jorm AF, Lubman DI. Parenting factors associated with reduced adolescent alcohol use. A systematic review of longitudinal studies. Aust N Z J Psychiatry. 2010; 44(9):774-83.

22. Mares SH, van der Vorst H, Engels RC, Lichtwarck-Aschoff A. Parental alcohol use, alcohol-related problems, and alcohol-specific attitudes, alcohol-specific communication, and adolescent excessive alcohol use and alcohol-related problems: An indirect path model. Addict Behav. 2011; 36(3):209-16.
23. Foundation for Advancing Alcohol Responsibility. Parents and Kids Both Say: The Leading Influence in Their Decision to Not Drink Alcohol Underage Is...Parents [Online]. 2013 Available from http:// responsibility.org/media_center/parents-and-kids-both-say-the-leadinginfluence-in-their-decision-to-not-drink-alcohol-underage-is-parents/.

24. Department of Health. Manila, Philippines: Online National Electronic Injury Surveillance System [Online]. 2013 [cited 2016 May 21]. Available from http://uhmis4.doh.gov.ph/doh_neiss.

25. National Institute on Alcohol Abuse and Alcoholism. NIAAA Factsheet [Online]. 2011 [cited 2016 May 21]. Available from http://pubs.niaaa. nih.gov/publications/Newsletter/Spring2011/newpub.htm.

26. US Department of Transportation (National Highway Traffic Safety Administration Washington, DC). Traffic Safety Facts 2002: Alcohol .A Public Information Fact Sheet on Motor Vehicle and Traffic Safety Published by the National Highway Traffic Safety Administration's National Center for Statistics and Analysis. National Center for Statistics and Analysis; 2003. Report No. DOT HS 809606.

27. U.S. Department of Transportation (National Highway Traffic Safety Administration National Center for Statistics and Analysis, NPO-121 400 Seventh Street, S.W. Washington, D.C). Fatality Analysis Reporting System General Estimates System .2004 DATA SUMMARY. December 2005 Report No: DOT HS 809920.

28. Valenzuela E, Fernandez M. The sequence of drug use: testing the gateway hypothesis in Latin America. The Journal of International Drug, Alcohol and Tobacco Research. 2011; 1(1):1-8.

29. Kandel DB, Yamaguchi K, Chen K. Stages of progression in drug involvement from adolescence to adulthood: further evidence for the gateway theory. J Stud Alcohol. 1992; 53(5):447-57.

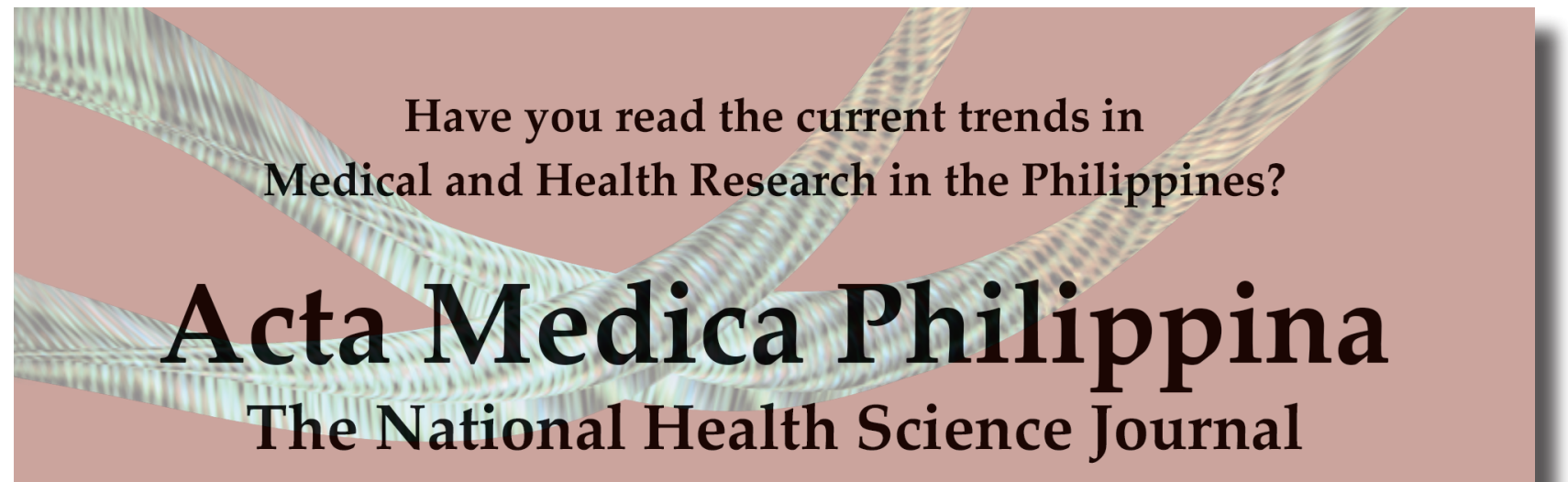

Now available for free at the Apple app store and Google play store. Available on the - Google play 